\section{Surgical Management of Trismus Due to Oral Submucous Fibrosis Using Diode Laser}

\author{
Shubham Agarwal ${ }^{1 *}$, Swati Agarwal ${ }^{2}$ and Shashidhar $\mathrm{K}^{3}$ \\ ${ }^{1}$ Department of ENT, SMS Medical College, Jaipur, Rajasthan, India \\ ${ }^{2}$ Department of Pathology, SMS Medical College, Jaipur, Rajasthan, India \\ ${ }^{3}$ Department of ENT, KIMS Medical College, Hubli, Karnataka, India
}

\begin{abstract}
Introduction: Oral submucous fibrosis is a chronic disease characterised by progressive inability to open the mouth. Various treatment modalities are available for its management, but these have largely been in-effective.

Materials and methods: Thirty cases fulfilling the inclusion criteria underwent a fibrous band release procedure using a diode laser.

Results: Patients were followed for 6 months and mouth openings compared. Encouraging results were achieved which were statistically significant.

Conclusion: This study indicated that management of oral submucous fibrosis can be achieved surgically using diode laser with minimal morbidity and great results.
\end{abstract}

Keywords: Diode laser; Laser assisted fibrous band lysis; OSMF

\section{Introduction}

OSMF has been well established in Indian medical literature since the time of Sushruta and was termed as 'Vidari' [1]. Pindborg defined OSMF as, "an insidious, chronic disease affecting any part of the oral cavity and sometimes the pharynx. Although occasionally preceded by and/or associated with vesicle formation, it is always associated with juxta-epithelial inflammatory reaction followed by fibroelastic change of the lamina propria, with epithelial atrophy leading to stiffness of the oral mucosa and causing trismus and inability to eat" [2].

Geographically, OSMF has a specific distribution and affects predominantly Asians (and particularly Indians) from the southern

*Corresponding author: Shubham Agarwal, Department of ENT, SMS Medical College, Jaipur, Rajasthan, India, Tel: +91 9660009870; E-mail: drshubz.jpr@ gmail.com

Citation: Agarwal S, Agarwal S, Shashidhar K (2015) Surgical Management of Trismus Due To Oral Submucous Fibrosis Using Diode Laser. J Otolaryng Head Neck Surg 1: 002

Received: July 24, 2015; Accepted: September 06, 2015; Published: September 30, 2015 states and Taiwanese [3]. Overall prevalence by gender varies from $0.2-2.3 \%$ in males and $1.2-4.57 \%$ in females [4]. Most of them are in the age group of 20-40. Areca nut is the main aetiological factor for OSMF.

Medical management is based on use of steroids, interferon gamma, placental extracts, vasodilators, etc. Certain modifications of these regimes include dietary supplementation with Iron and vitamins. Injections of degradative enzymes have been tried [5-7].

This condition does not regress either spontaneously or with cessation of betel quid chewing. Release of fibrotic bands by surgical means in moderately advanced to advanced cases with trismus is necessary.

In this article, we would like to report our experience of treating 30 patients of oral sub-mucous fibrosis using diode laser and to discuss upon opting the fore-mentioned tool in the study.

\section{Aims and Objectives}

To access the efficacy of diode laser in the effective increase in mouth opening of oral submucous fibrosis induced trismus.

\section{Classification used for Management of Trismus}

Various classifications have been given but the latest and the accepted one used in this study is (Table 1).

\begin{tabular}{|c|c|}
\hline & Clinical staging \\
\hline Stage 1. (S1) & Stomatitis and/or blanching of oral mucosa. \\
\hline Stage 2. (S2) & $\begin{array}{l}\text { Presence of palpable fibrous bands in buccal mucosa and/or } \\
\text { oropharynx, with/without stomatitis }\end{array}$ \\
\hline Stage 3. (S3) & $\begin{array}{l}\text { Presence of palpable fibrous bands in buccal mucosa and/or } \\
\text { oropharynx, and in any other parts of oral cavity, with/without } \\
\text { stomatitis. }\end{array}$ \\
\hline \multirow[t]{2}{*}{ Stage 4. (S4) } & $\begin{array}{l}\text { A. Any one of the above stage along with other potentially } \\
\text { malignant disorders e.g. oral leukoplakia, oral erythroplakia, etc. } \\
\text { B. Any one of the above stage along with oral carcinoma. }\end{array}$ \\
\hline & Functional staging \\
\hline M1 & Inter-incisal mouth opening up to or $>35 \mathrm{~mm}$. \\
\hline M2 & Inter-incisal mouth opening between $25 \mathrm{~mm}$ and $35 \mathrm{~mm}$. \\
\hline M3 & Inter-incisal mouth opening between $15 \mathrm{~mm}$ and $25 \mathrm{~mm}$. \\
\hline M4 & Inter-incisal mouth opening $<15 \mathrm{~mm}$. \\
\hline
\end{tabular}

The functional staging has been considered as the basis of management.

\section{Materials and Methods}

Patients attending ENT OPD during the study period of 1 year who have fulfilled the inclusion criteria were enrolled in the study.

\section{Inclusion criteria}

- Patient complaining of restricted mouth opening with fibrous bands present over the buccal mucosa, hard palate, anterior faucial pillars or oropharynx proven histopathologically to be oral submucous fibrosis. 
Citation: Agarwal S, Agarwal S, Shashidhar K (2015) Surgical Management of Trismus Due To Oral Submucous Fibrosis Using Diode Laser. J Otolaryng Head Neck Surg 1: 002 .

- Inter-incisal Distance (I.D) $<2.5 \mathrm{~cm}$ i.e., $\mathrm{M} 3$ and $\mathrm{M} 4$ group according to the above mentioned classification.

- Fully informed valid consent of the patient towards this incurable chronic fibro-elastic scarring disease to avoid raising expectations.

\section{Exclusion criteria}

- Patient labeled histological having pre-malignant or malignant changes.

- Patients where zero degree endoscope can't be introduced for visualization of retro-molar fibrotic bands.

- Patients with Temporo-mandibular joint problems or any cause of trismus other than OSMF.

- Patients who are immune-compromised and with bleeding disorders.

\section{Design of study}

A prospective study was conducted with total of 30 cases. Patients with measured inter-Incisal Distance (I.D) $<2.5 \mathrm{~cm}$ were first confirmed histopathologically and then treated surgically-diode laser assisted fibrous band lysis under general anesthesia.

\section{Surgical technique}

- Patient made to lie supine and naso-tracheally intubated. A 30 degree head elevation given. Fergusson's mouth gag introduced.

- An incision was lased inferiorly over the buccal mucosa starting from the retro-molar trigone area extending up to the $1^{\text {st }}$ pre-molar region. A similar second incision was placed superior to this by beginning from $1 / 3$ of the inferior incision in third molar area extending obliquely to form an inverted " $Y$ ".

- The incisions were made approx. $2 \mathrm{~mm}$ deep until the muscle layer reached, incising only the fibrous mucosa and sub-mucosal layer.

- Laser beam was delivered at 10 watt continuous mode. A similar incision was placed bilaterally, and the mouth was then forced open (intra-operatively) using the same mouth gag.

- Mouth opening recorded with the help of callipers. The mouth opening was measured from the edges of the mandibular and maxillary central incisors.

- The average surgical time for the procedure was 20-30 minutes. There was minimal intra-operative blood loss.

- The main complaint expressed by the patients during the immediate post-operative period was pain, which was controlled with adequate analgesia.

- Post-op physiotherapy exercises started the same day of surgery using a dental bite block and patients were discharged two to three days after the operation.

- Patients who complied with mouth-stretching exercises using the dental bite block and a regular follow up for a period of six months were only included in the study (Figure 1).

\section{Observation and Results}

Majority of the patients were in an age group of 20 to 40 years with male predominance. The youngest case was 16 year old and the oldest case was 57 year old. Average age of cases was 27.6 years.

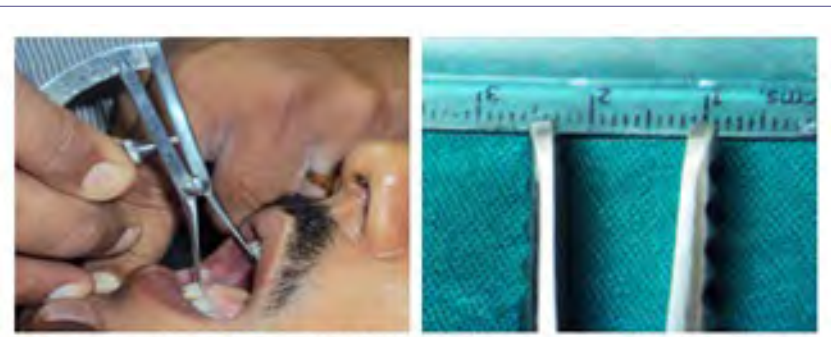

Mouth Opening Pre Operation Mouth Opening Pre Operation

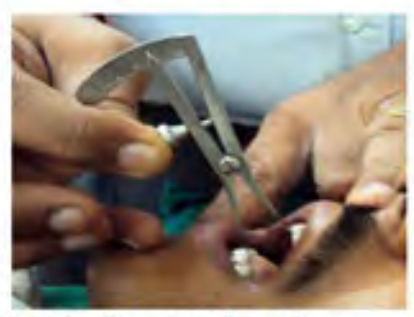

Mouth Opening After Laser Treatment

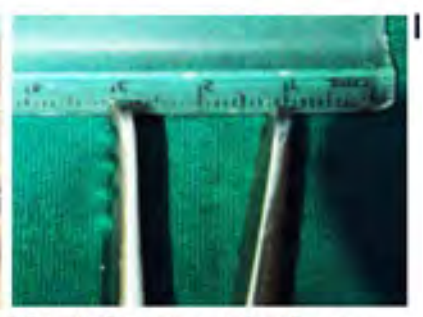

Mouth Opening After Laser Treatment
Figure 1: Comparison of pre and post OP mouth openings.

All these patients with Trismus had associated burning sensation in oral cavity which was statistically highly significant $(\mathrm{p}<0.001)$ but only some patients had other associated complaints such as difficulty in tongue protrusion, dysphagia, ear complaints i.e., discharge or decreased hearing etc., which was insignificant [test of proportion $(\mathrm{z})=1.8]$.

The inter-incisal distance measured pre and post treatment at regular intervals (immediate, $7^{\text {th }}, 15^{\text {th }}, 30^{\text {th }}, 60^{\text {th }}, 90^{\text {th }}, 180^{\text {th }}$ day) and compared using Paired Student t-test.

Immediate post-operative observation and results are mentioned in Table 2, Chart 1, Figure 2 and 3.

\begin{tabular}{|c|c|c|c|c|c|c|}
\hline & Mean & $\mathbf{N}$ & $\begin{array}{c}\text { Std. } \\
\text { Deviation }\end{array}$ & $\begin{array}{c}\text { Std. Error } \\
\text { Mean }\end{array}$ & t-value & p-value \\
\hline At presentation & 1.89 & 30 & .464 & .085 & & \\
\hline At post-op & 2.87 & 30 & .647 & .118 & -19.745 & 0.0001 \\
\hline At 1 month & 2.39 & 30 & .717 & .131 & -6.380 & 0.0001 \\
\hline At 3 month & 2.38 & 30 & .724 & .132 & -7.099 & 0.0001 \\
\hline At 6 month & 2.44 & 30 & .730 & .133 & -8.040 & 0.0001 \\
\hline
\end{tabular}

Table 2: Comparison of increase in I.D at various time intervals to that of presentation.

For Inter-incisal Distance (I.D) at various time intervals, $p<0.0001$ which is highly significant.

\section{Discussion}

Behind a restricted mouth lies a restricted personality"- this is more or less true for the patients suffering from the highly perplexing disease called oral submucous fibrosis.

The higher predominance in areca nut usage by males may be due to the ease and places in which they can buy the product as compared to females. In addition females are more health conscious and chewing in females has a negative aesthetic value. Due to increase in availability of areca nut and pan masala sachets in multi-attractive packings with extensive publicity by the manufacturers also play a major role in targeting the younger population.

The most accepted etiological factor is the concept of chewing betel nut and tobacco in its various forms. Other predisposing factors 
Citation: Agarwal S, Agarwal S, Shashidhar K (2015) Surgical Management of Trismus Due To Oral Submucous Fibrosis Using Diode Laser. J Otolaryng Head Neck Surg 1: 002.

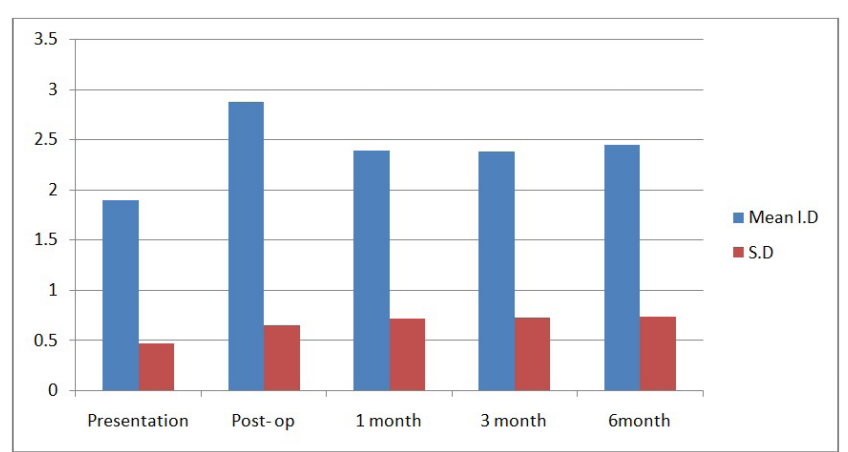

Chart 1: Showing the cumulative comparison of mean of I.D and standard deviation at various time intervals to that of presentation.

Average gain in inter-incisal distance after 6 months post treatment is $6 \mathrm{~mm}$.

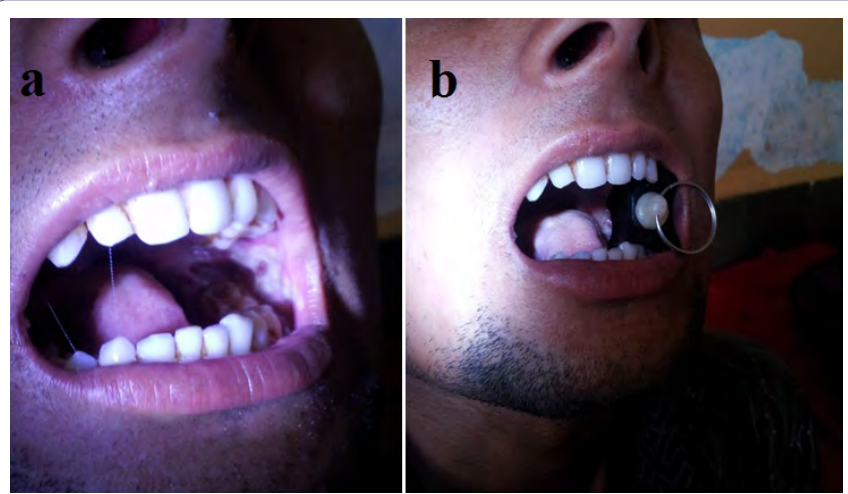

Figure 2: a) Immediate post-op, b) Performing bite block.

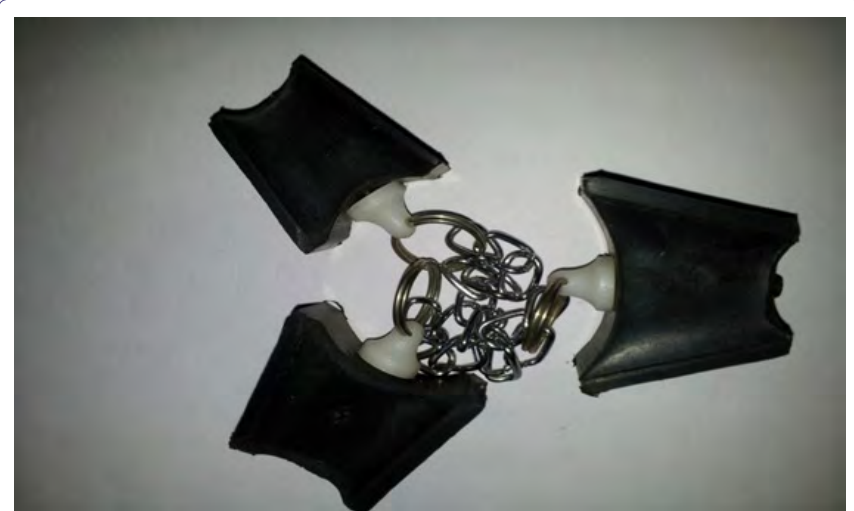

Figure 3: Bite blocks used for post-op exercise.

such as autoimmunity, collagen disorders, genetic susceptibility and nutritional factors also play a vital role.

Medical management with local injections of corticosteroids and hyaluronidase, along with systemic ingestion of multivitamins, anti-oxidants apparently has been known to decrease the burning sensation. Local physiotherapy, in the form of hot rinses or selective deep heating therapies (such as short wave diathermy), does not produce any beneficial effects [5,9]. Use of intra-lesional g interferon, an antifibrotic cytokine, has been shown to reduce the burning sensation and to improve mouth-opening [5].

Steroids act by opposing the action of soluble factors released by sensitized lymphocytes following activation by specific antigens steroids, act as immunosuppressive agents. It also prevents or suppresses inflammatory reactions thereby preventing fibrosis by decreasing fibroblastic proliferation and deposition of collagen. The initial symptomatic relief could be due to the anti-inflammatory action of the steroids, which helps in clearing the juxta-epithelial inflammation [10].

Hyaluronidase causes breakage and dissolution of fibrous bands thus providing relief from the condition. By virtue of its specific action on hyaluronic acid, which plays an important role in the formation of collagen, hyaluronidase may be responsible for the better results in patients with restricted mouth opening [10].

Surgical management is indicated in moderately advanced to advanced cases of oral submucous fibrosis, as defined by maximum mouth-opening of $25 \mathrm{~mm}$ [8].

Simple division of fibrotic bands with secondary healing has resulted in more fibrosis and disability [4]. Reconstruction of the resultant defect is problematic and various methods have been described including split thickness skin grafts, Buccal Fat Pad (BFP) grafts [11], microvascular free radial forearm flaps [4], tongue flap [12] and nasolabial flap [13]. Additional procedures like masticatory muscle myotomy and bilateral coronoidectomy can be performed to enhance mouth opening.

Use of flaps has the following disadvantages [9]:

\section{- Time consuming}

- Scarring at the graft host site

- Increased hospital stay

- Possibility of graft failure (in free flaps)

\section{- Possible necessity of secondary procedures like debulking}

All the above described methods of reconstruction are either prone to early recurrence of fibrosis or more importantly, in the setting of a pre-cancerous lesion, make regular monitoring of the affected mucosa for carcinomatous change difficult or even impossible [14].

Traditional methods of releasing the fibrotic bands with cold knife are associated with increased per-operative bleeding which is difficult to control in the presence of severe trismus. Moreover introduction of surgical instruments into the operative site is difficult.

Electro surgical techniques, though associated with reduced blood loss have the major disadvantage of deep tissue damage, which in turn leads to increased post operative fibrosis and thus negates the early gains achieved [14].

Among all the lasers available, of the numerous properties, penetration and absorption of rays are the two most relevant parameters for selection of diode laser in our study. Diode laser is a portable device which delivers rays through a fibre-optic cable and hence can be delivered to relatively "difficult-to-access" areas. Its cutting depth is less than $0.01 \mathrm{~mm}$, and thus preserves tissues beyond this depth.

Diode laser offered several advantages over conventional surgical procedures like:

- The procedure done is a less time consuming technique with minimal morbidity

- Haemostatic nature of the surgery which allows surgery to be performed more precisely and accurately because of increased visibility and accessibility of the surgical site 
Citation: Agarwal S, Agarwal S, Shashidhar K (2015) Surgical Management of Trismus Due To Oral Submucous Fibrosis Using Diode Laser. J Otolaryng Head Neck Surg 1:002.

- Decreased post operative pain and swelling

- Causes a reduction in bacterial counts thereby promoting quicker, more predictable healing with minimal post operative infection and inflammation

- Leads to healing with minimal scarring

Definite increase in mouth opening observed at post-op which eventually decreases over the next 3 months and later it stabilizes by around 6 month. This gradual decrease could be attributed to fibrosis of the tissue while healing.

\section{Summary}

Surgical management using diode laser should be encouraged in moderately advanced to advanced cases over conventional procedures. Advantage being laser creates précised incisional marks, the defect is neither closed nor covered by any flaps and an excellent cosmetic and functional result is achieved.

Procedure is less time-consuming and more economical due to a shortened hospital stay which resulted in better patient satisfaction and compliance.

\section{References}

1. Schwartz J (1952) Atrophia idiopathica (tropica) mucosaoris. Demonstrated at the $11^{\text {th }}$ International Dental Congress, London, UK.

2. Pindborg JJ, Sirsat SM (1966) Oral submucous fibrosis. Oral Surg Oral Med Oral Pathol 22: 764-779.

3. Angadi PV, Rao SS (2011) Areca nut in pathogenesis of oral submucous fibrosis: revisited. Oral Maxillofac Surg 15: 1-9.
4. Wei FC, Chang YM, Kildal M, Tsang WS, Chen HC (2001) Bilateral small radial forearm flaps for the reconstruction of buccal mucosa after surgical release of submucosal fibrosis: a new, reliable approach. Plast Reconstr Surg 107: 1679-1683.

5. Haque MF, Meghji S, Nazir R, Harris M (2001) Interferon gamma (IFN-gamma) may reverse oral submucous fibrosis. J Oral Pathol Med 30: 12-21.

6. Kakar PK, Puri RK, Venkatachalam VP (1985) Oral submucous fibrosis--treatment with hyalase. J Laryngol Otol 99: 57-59.

7. Gupta DS, Gupta MK, Golhar BL (1980) Oral submucous fibrosis-clinical study and management of physiofibrolysis (MWD). Journal of the Indian Dental Association 52: 375-378.

8. More CB, Das S, Patel H, Adalja C, Kamatchi V, et al. (2012) Proposed clinical classification for oral submucous fibrosis. Oral Oncol 48: 200-202.

9. Nayak DR, Mahesh SG, Aggarwal D, Pavithran P, Pujary K, et al. (2009) Role of KTP-532 laser in management of oral submucous fibrosis. J Laryngol Otol 123: 418-421.

10. Juhi G, Srinivasan SV, Jonathan D (2012) Effiacy of betamethasone, placental extract and hyaluronidase in the treatment of OSMF: A comparative study. e-Journal of Dentistry 2: 132.

11. Yeh CJ (1996) Application of the buccal fat pad to the surgical treatment of oral submucous fibrosis. Int J Oral Maxillofac Surg 25: 130-133.

12. Golhar S, Mahore MN, Narkhede S (1988) Tongue Flap in OSMF. Ind J Otolaryng 41: 104-107.

13. Kavarana NM, Bhathena HM (1987) Surgery for severe trismus in submucous fibrosis. Br J Plast Surg 40: 407-409.

14. Mohan K, Dilip R, Anand Kumar RS, Sathiya M (2006) Surgical management of trismus due to oral Submucous fibrosis - lysis of fibrotic bands With the KTP-532 laser. Indian J Otolaryngol Head Neck Surg 58: 229-31. 